\title{
Study of the deformation mechanism of the Gaoliying ground fissure
}

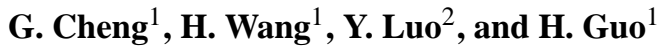 \\ ${ }^{1}$ China Institute of Geo-environment Monitoring, Beijing 100081, China \\ ${ }^{2}$ Beijing Institute of Geo-environment Monitoring, Beijing 100195, China \\ Correspondence to: G. Cheng (chenggm@mail.cigem.gov.cn) \\ Published: 12 November 2015
}

\begin{abstract}
The Gaoliying ground fissure in Beijing has caused building cracking and road damage, and has seriously influenced city construction. Based on investigations and trenching, the influences of the fault and the variation of groundwater levels on the formation mechanism of the Gaoliying ground fissure were investigated by using FLAC3D. The results indicated that (1) the surface location of Gaoliying fissure is controlled by the underlying normal fault activity, and over pumping further exacerbates development of the ground fissure; (2) when the groundwater level declines, obvious differential settlement occurs at both sides of the ground fissure, in which greater settlement occurs in the vicinity of the hanging wall, the greater the distance from the hanging wall, the smaller the ground subsidence, however smaller ground subsidence occurs in the vicinity of the footwall, the greater the distance from the footwall, the greater the ground subsidence; (3) the vertical velocity of the ground fissure triggered by the fault activity and groundwater decline ranges from 15.5 to $18.3 \mathrm{~mm} \mathrm{a}^{-1}$, which is basically in line with the monitoring data. The fault activity contributes about $28-39 \%$, and the groundwater contributes about $61-72 \%$ to the deformation of the ground fissure, respectively.
\end{abstract}

\section{Introduction}

Ground fissures are common in many parts of the world, and have been particularly well documented in the United States and in China (Holzer, 1980; Zellmer et al., 1985; Peng, 2012). Many fissures appear similar to those caused by groundwater withdrawal and related ground subsidence (Lister and Secrest, 1985; Lee et al., 1996). In China, the earliest ground fissures were detected at the end of 1950s (Peng et al., 2013). Now ground fissures have been a main geological hazard developed in north China (Wang, 2000; Wang et al., 2001), especially in Gaoliying district in Beijing, which has led to great losses to local economies and has created a large potential danger to human living (Jia and Guo, 2007).

Jia (2010) and Jia et al. (2011) suggests that the Gaoliying ground fissure is controlled by the Gaoliying fault, and its formation is the result of fault creep deformation and the differential settlement caused by groundwater recession. However, there are still some critical problems not yet solved, for example, How does the activity of underlying faults generate and aggravate the formation and the activity of the ground fissures? What important roles do the tectonic activity and the over-pumping play in the formation of the ground fissures? The influence of fault activities and the groundwater level changes on the Gaoliying fissure based on the measured data was simulated using FLAC3D in this paper. The results provide insight as to the specific contribution of fault activities and groundwater on ground fissure formation, and infers the mechanism for deformation of the fissure.

\section{Outline of Gaoliying ground fissure}

The Gaoliying fissure in Beijing was first discovered in the $1990 \mathrm{~s}$, and the fissure trend is approximately from northeast $45^{\circ}$ to northeast $60^{\circ}$, which is consistent with the underlying Huangzhuang-Gaoliying fault. It extends north-eastward from the Xiwang Village to the North sixth ring road (Fig. 1). The fissure has a length of about $6000 \mathrm{~m}$, with a width ranging from a few millimeters to hundreds of millimeters, in which the maximum width is $200 \mathrm{~mm}$. The obvious ground 


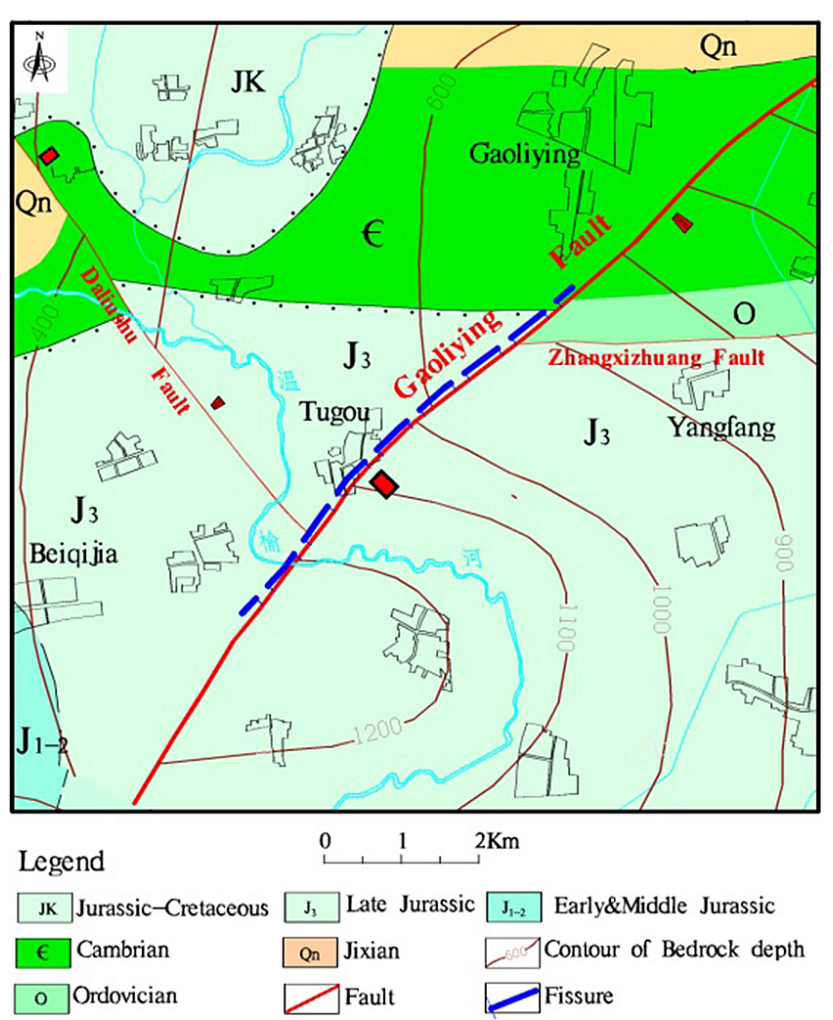

Figure 1. The plan distribution map of Gaoliying fissure and fault.

dislocation occurred at both sides of the fissure, in which the northwest is higher than the southeast, and has caused buildings cracking and has destroyed roads. The data from a ground fissure monitoring station shows that the maximum vertical displacement rate of Gaoliying fissure is $18 \mathrm{~mm} \mathrm{a}^{-1}$.

\section{Geological background}

The Gaoliying fault is an important active fault in the Beijing plain area. Its trend is NNE with a length of $132 \mathrm{~km}$. The fault is the main control fault of the west boundary of Beijing depression in the Tertiary, and Shunyi and Huairou secondary depressions were formed during the Quaternary period. The fault is a normal fault with dip-slip characteristics.

According to the characters of the Quaternary kinematics analysis, the Gaoliying fissure is divided into three parts: the Miaocheng-Gaoliying section (North section, $40 \mathrm{~km}$ ), the Huangzhuang section (Middle section, $52 \mathrm{~km}$ ), and the Laishui section (South section, $40 \mathrm{~km}$ ). The Gaoliying fissure is within the Huangzhuang section. Shallow seismic exploration reveals that the fall of the Quaternary system on both sides of the fault near Gaoliying fissure ranges from 140 to $280 \mathrm{~m}$. The seismic exploration at Tugou village indicates that the thickness of the Quaternary sediments at the footwall and hanging wall is respectively $460-500$ and 660 $740 \mathrm{~m}$, in which the thickness difference on both sides of the

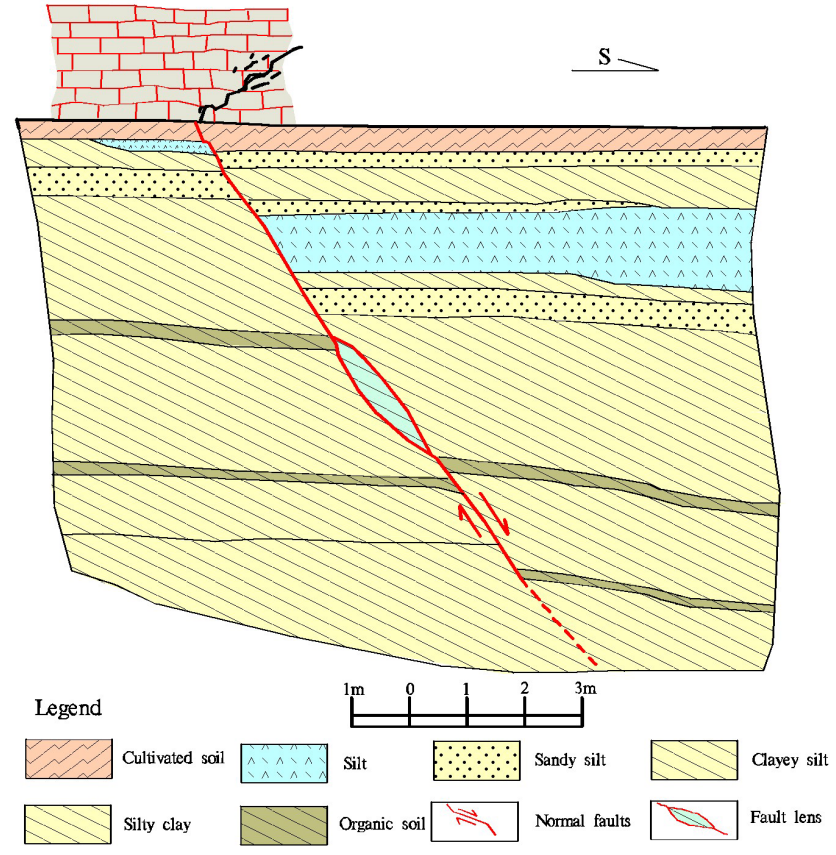

Figure 2. The profile of Gaoliying ground fissure according to trench data.

fault is $200-240 \mathrm{~m}$. The Gaoliying fault location corresponds to the Gaoliying ground fissure. An exploratory trench disclosed that the dislocation distance of the fault at the surface layer is much as $3.56 \mathrm{~m}$ (Fig. 2). Boring data revealed that the dislocation distance of fault in the shallow strata is smaller, whereas the dislocation distance of fault in the deep strata is larger. The dislocation distance of fault at the depth of about $50 \mathrm{~m}$ is approximately $8 \mathrm{~m}$.

The study area is located on the Wenyu Alluvial Fan plain area, its surface is covered with Quaternary strata. The deposit is relatively simple, and is dominated by fluvial sediments. Table 1 shows the results of geophysical exploration data on both sides of the fault and bedrock bench mark data acquired by the ground settlement monitoring station on both sides of ground fissures.

\section{Numerical model}

\subsection{Conceptual model}

The numerical model is $2000 \mathrm{~m}$ in $X$ direction, $1000 \mathrm{~m}$ in $Y$ direction and $20 \mathrm{~m}$ in $Z$ direction. The model contains 11440 elements and 11886 grid points (Fig. 3). Horizontal translation is confined at the lateral boundary and vertical translation in the footwall is confined, whereas vertical translation in the hanging wall is free at the bottom boundary in the model. 
Table 1. The simplified strata used in the numerical model.

\begin{tabular}{|c|c|c|c|c|c|c|c|c|}
\hline Stratum name & Silty clay & Silt & Sand & Silty clay & Sandy and silty & Silty clay & Sandy and silty & Bedrock \\
\hline Thickness of hanging wall (m) & 25 & 35 & 70 & 70 & 150 & 250 & 250 & 150 \\
\hline Thickness of footwall (m) & 20 & 30 & 50 & 50 & 50 & 100 & 150 & 550 \\
\hline $\begin{array}{l}\text { Separation of the hanging wall } \\
\text { and footwall top (m) }\end{array}$ & 0 & 5 & 10 & 30 & 50 & 150 & 300 & 400 \\
\hline
\end{tabular}

Table 2. The physical and mechanical parameters of each stratum in the model.

\begin{tabular}{lccccccc}
\hline Material & $\begin{array}{c}\text { Density } \\
\left(\mathrm{kg} \mathrm{m}^{-3}\right)\end{array}$ & $\begin{array}{c}\text { Elastic modulus } \\
(\mathrm{GPa})\end{array}$ & Poisson's ratio & $\begin{array}{c}\text { Cohesion } \\
(\mathrm{kPa})\end{array}$ & $\begin{array}{c}\text { Strength of } \\
\text { extension } \\
(\mathrm{kPa})\end{array}$ & $\begin{array}{c}\text { Internal friction } \\
\text { angle } \\
\left({ }^{\circ}\right)\end{array}$ & $\begin{array}{c}\text { Dilatancy angle } \\
\left({ }^{\circ}\right)\end{array}$ \\
\hline Silty cla & 1750 & 0.05 & 0.35 & 50 & 20 & 20 & 10 \\
Silt & 1850 & 0.06 & 0.33 & 40 & 10 & 22 & 10 \\
Sand & 1950 & 0.1 & 0.3 & 10 & 5 & 22 & 10 \\
Silty clay & 1850 & 0.2 & 0.33 & 50 & 20 & 10 & 20 \\
Sandy and silty & 1950 & 0.5 & 0.3 & 30 & 30 & 21 & 10 \\
Silty clay & 1950 & 0.5 & 0.3 & 60 & 40 & 20 & 10 \\
Sandy and silty & 2000 & 0.8 & 0.3 & 40 & 0 \\
Bedrock & 2500 & 10 & 0.25 & 10000 & 3000 & 0.2 & 0 \\
Fracture surface & 1850 & 0.1 & 0.2 & 2 & 0.2 & 0 \\
\hline
\end{tabular}

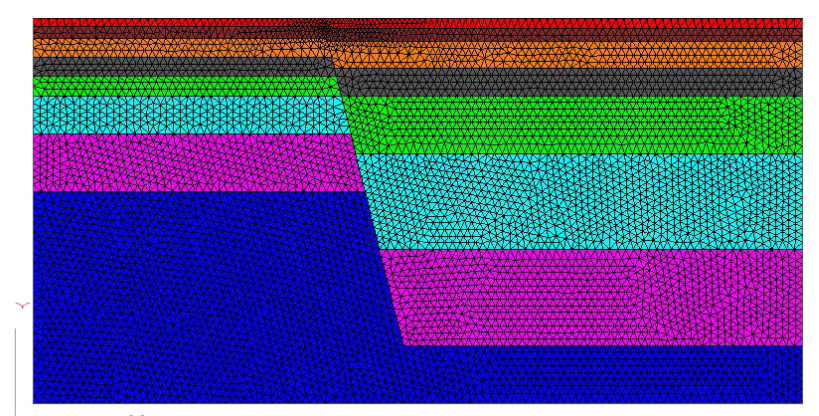

Figure 3. Numeric simulation structure of Gaoliying fissure.

\subsection{Material parameters}

In order to simplify the calculation, the Mohr-Coulomb constitutive relation is used for the analysis, and parameter characteristics of different materials are shown in Table 2. In addition, the fracture surface is treated as a weak interface, and its material parameters are separately set.

\subsection{Modelling schemes}

Based on the bedrock bench mark data from Tianzhu monitoring station and the Baxianzhuang monitoring station on both sides of the Gaoliying fissure, the annual differential settlements are $8,6.5,4.8$, and $6.7 \mathrm{~mm}$ respectively between 2009 and 2012, which indicates that bedrock on both sides of the fault has been in a state of activity, in which the hanging wall declines relative to the footwall. The long-term ground- water observation hole near the Gaoliying fissure shows that the groundwater level is about $20 \mathrm{~m}$, and the rate of decline of the water level can reach $2 \mathrm{~m} \mathrm{a}^{-1}$.

Therefore, three kinds of modeling schemes are considered in this simulation, i.e., the relative decline rate of bedrock between the hanging wall and the footwall is $4.8 \mathrm{mma}^{-1}$ (Scheme 1) and $8 \mathrm{mma}^{-1}$ (Scheme 2), and the groundwater decline rate is $2 \mathrm{ma}^{-1}$ (Scheme 3 ).

\subsection{Simulation results}

Figures 4 and 5, show that the surface location of the ground fissure is controlled by the underlying normal fault, and it is in agreement with the fault. When the activity velocity of the bedrock inside the fault is $4.8 \mathrm{~mm} \mathrm{a}^{-1}$, the maximum differential settlement of the ground fissure is $4.4 \mathrm{~mm} \mathrm{a}^{-1}$; when the activity velocity of the bedrock inside the fault is $8 \mathrm{~mm} \mathrm{a}^{-1}$, the maximum differential settlement of the ground fissure is $7.2 \mathrm{mma}^{-1}$ (Fig. 6).

From Fig. 6, it can be seen that when the groundwater level declines, subsequent differential settlement occurs on both sides of the ground fissure, in which greater ground subsidence occurs in the vicinity of the hanging wall. The greater the distance from the hanging wall the smaller the ground subsidence, however small ground subsidence also occurs in the vicinity of the footwall where the greater the distance from the footwall, the greater the ground subsidence, and the maximum differential settlement of the ground fissure is as much as $11.1 \mathrm{~mm}$. 


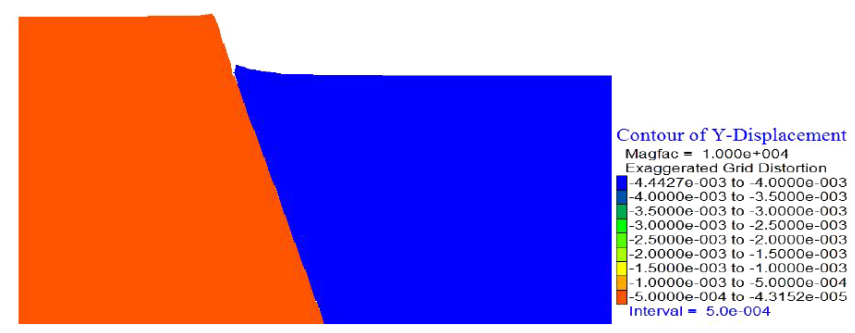

Figure 4. The annual settlement in scheme 1 (scaled up to 10000 times of the original.

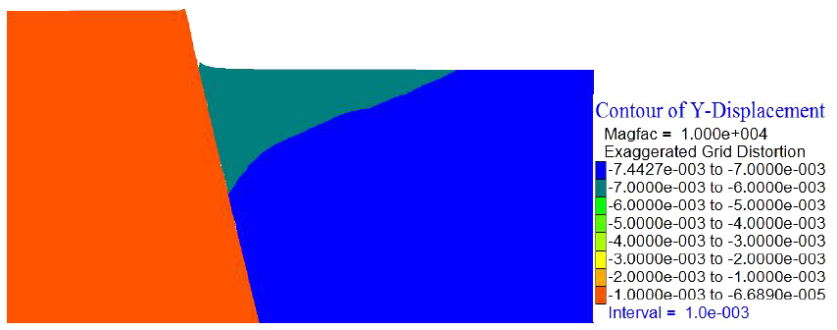

Figure 5. The annual settlement in scheme 2 (scaled up to 10000 times of the original).

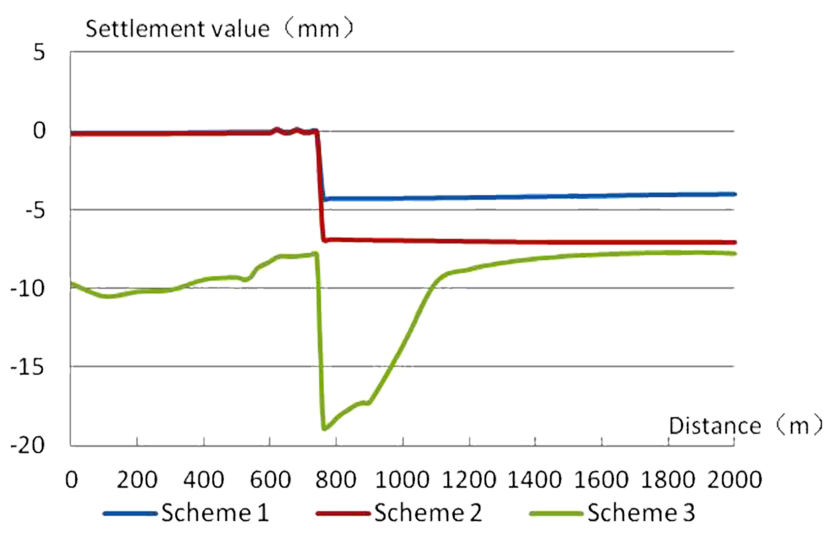

Figure 6. The annual ground settlement at both sides of the ground fissure under different schemes.

The vertical velocity of the ground fissure triggered by the fault activity and over pumping (groundwater level decline) can reach to $15.5-18.3 \mathrm{~mm} \mathrm{a}^{-1}$, which is basically in line with the monitoring data. In which the fault activity contributes about 28-39\%, and the groundwater contributes about $61-72 \%$ to deformation of the ground fissure.

\section{Conclusions}

1. The surface location of the Gaoliying fissure is controlled by the underlying normal fault activity. Differential settlement occurs at both sides of the fault due to the fault activity, which induces the formation of ground fissure, and over pumping further exacerbates development of the ground fissure.

2. When the groundwater level declines, differential settlement occurs on both sides of the ground fissure, and greater settlement occurs in the vicinity of the hanging wall. The greater the distance from the hanging wall, the smaller the ground subsidence, however small ground subsidence also occurs in the vicinity of the footwall and the greater the distance from the footwall, the greater the ground subsidence.

3. The vertical velocity of the ground fissure triggered by the fault activity and groundwater decline ranges from 15.5 to $18.3 \mathrm{mma}^{-1}$, which is basically in line with the monitoring data. The fault activity contributes about 28-39\%, and the over pumping contributes about 61$72 \%$ to the deformation of the ground fissure, respectively.

Acknowledgements. This study was supported by the National Science Foundation of China (No. 41172266) and Geological Investigation Project of China (No. 12120115044901).

\section{References}

Holzer, T. L.: Faulting caused by groundwater level declines, San Joaquin Valley, California, Water Resour. Res., 16, 1065-1070, 1980 .

Jia, S.: Annual report of land subsidence monitoring in Beijing, Beijing Institute of Hydrogeology and Engineering Geology, 2010 (in Chinese).

Jia, S. and Guo, M.: The Relation between Huangzhung-Gaoliying fault and fissure by Gaoliying Trench, City Geology, 4, 24-28, 2007 (in Chinese).

Jia, S., Wang, H., and Ye, C.: Investigation and survey methods appropriate for ground fissures in Beijing, Journal of Engineering Geology, 19 (suppl.), 104-111, 2011.

Lee, C., Zhang, J., and Zhang, Y.: Evolution and origin of the ground fissures in Xian, China, Eng. Geol., 43, 45-55, 1996.

Lister, A. L. and Secrest, D. C.: Giant desiccation cracks and differential surface subsidence, Red Lake Playa, Mohave County, Arizona, Bulletin of the Association of Engineering Geologists, 22, 299-314, 1985.

Peng, J.: The Geo-hazard of Xi' an Ground Fissures. Science Press, Beijing, 2012 (in Chinese).

Peng, J., Chen, L., Huang, Q., Men, Y., Fan, W., and Yan, J.: Physical simulation of ground fissures triggered by underground fault activity, Eng. Geol., 155, 19-30, 2013.

Wang, J., Wang, C., and Liu, K.: Progress in ground fissures and its hazard research, Advances in Earth Sciences, 16, 303-313, 2001 (in Chinese).

Wang, J. M.: Theory of Ground Fissures Hazards and Its Application, Science and Technology Press of Shaanxi, Xi'an, 2000 (in Chinese).

Zellmer, J. T., Roquemore, G. R., and Blackerby, B. A.: Modern tectonic cracking near Garlock Fault, California, Bull. Geol. Soc. Am., 96, 1037-1042, 1985. 